\title{
Reconfigurable Control of PWM AC-DC-DC Converter without Redundancy Leg Supplying an AC Motor Drive
}

\author{
Khaled Sahraoui ${ }^{*}$, Bachir Gaoui ${ }^{1}$ \\ 1 Department of Electrotechnical, Faculty of Technology, University Amar Telidji of Laghouat, P. O. B. G37, 03000 Laghouat, Algeria \\ * Corresponding author, e-mail: k.sahraoui@lagh-univ.dz
}

Received: 27 September 2019, Accepted: 25 March 2020, Published online: 09 February 2021

\begin{abstract}
The purpose of this paper is the study by simulation of a fault tolerant control with Pulse Width Modulation (PWM) AC-DC-AC converter supplying a three-phase rotor field oriented induction motor. The back to back converter, is supplied with three-phase network and composed of a PWM rectifier and a voltage source inverter. Fault tolerant topology of AC-DC-AC converter that without redundancy have been studied and associated with affective and fast method of fault detection and compensation to guarantee the continuity of service, in the presence of a possible open circuit failure on the level of one of their legs. Although of the presence of open circuit on the level of one of the converter legs the control based on the Zero Sequence Signal (ZSS) assure the service continuity, the simulation results obtained prove that it is possible to maintain the good performance of the drive without redundancy leg (6/5 topology).
\end{abstract}

\section{Keywords}

asynchrouns machine, converter without redundant leg, field oriented control, service continuity, sigmadelta PWM, three-phase AC-DC-AC converter

\section{Introduction}

Back-to-Back converters are widely used in various industrial areas such as electric machine drives, uninterruptible power supply, unified power quality conditioner and gridconnected renewable energy systems [1, 2]. A research survey has reported that the failure rates of these converter are $30 \%, 26 \%, 21 \%$ and $13 \%$ due to their capacitors, printed circuit boards, semiconductors, and soldering, respectively [2, 3]. Therefore, the reliability and performance of PWM converters has been paid a great deal of attention. Recently, fault detection and tolerant control techniques for power converters have attracted a lot of interest due to their higher reliability and lower maintenance.

Recently, the using of power electronic increase dramatically in industrial applications, in the most industrial applications, induction motors are predominantly fed from Pulse Width Modulation (PWM) voltage source inverter for variables speed operation [3]. Voltage threephase structure static converters are essential elements of many power electronic systems such as inverters machines alternatives, uninterruptible power supplies, and active filters $[4,5]$.
The security of these systems, their reliability, performance, power quality and continuity of service are today the major concerns in the field of energy [6]. PWMinduction motors are usually more reliable than those supplied directly online. For instance, the problem of faults can occur in the machine or in the converter [7-10].

The use of converters has some drawbacks because the power electronic converters came with an increased possibility of component failures [6]. The failures of a power converter, whether from drivers, its close control, a controllable power components, lead to loss total or partial control of currents in phases. These failures can cause serious system malfunctions. Indeed, it would endanger the system in some cases if the defect is not detected quickly and compensated $[2,10]$.

Several researchers in the fault tolerant converter applications have obtained promising results by using an additional leg to guarantee the continuity of service, in [2], the authors studied the fault tolerant six-leg converter for a Wind Energy Conversion System (WECS) with a DoublyFed Induction Generator (DFIG). In [11-14], the authors treated the fault detection, isolation and compensation 
as an open-circuit and short-circuit tolerant motor drive system and discusses about fault tolerant AC-DC-AC single-phase to three-phase converter.

The approach introduced here minimizes the time interval between the fault occurrence and its diagnosis. This paper demonstrates the possibility to detect a faulty switch in less than $40 \mu$ s by using a time criterion instead of voltage criterion. In this paper, a more general fault tolerant converter without redundancy is proposed for the back-to back three phase two level converters based on a 6/5 leg topology. More general, fault tolerant converter without redundancy leg is proposed for the induction motor drives. The studied system is described briefly in Section 2. In Section 3, a modeling and control of the two sides of our converter and the induction machine are devoted. The fault detection and control schemes method are used as in $[4,6,15]$ discussed in Section 4. Finally, fully simulation results are provided in Sections 5 and 6. The obtained simulation results here prove that the continuity of service is assured although the presence of faults in the switches.

\section{System description}

A technical advantage of the voltage converter PWM from the decoupling capacitor placed between the network-side converter and the machine side of the converter. The network side converter provides sinusoidal currents and voltage regulation of the DC bus and the machine side of the converter which assure the control thereof. This will provide some protection and separate controls for the two sides. By against the important inconvenience of this voltage converter PWM lies in the switching losses and reduce the overall life of the system see in Fig. $1[1,14]$.

\section{Modeling and control of studied system}

\subsection{Modeling of grid side converter}

A PWM rectifier is simply a voltage inverter used in reverse. It produces a DC voltage from an AC supply, it is built based on bidirectional semiconductor components. Also it

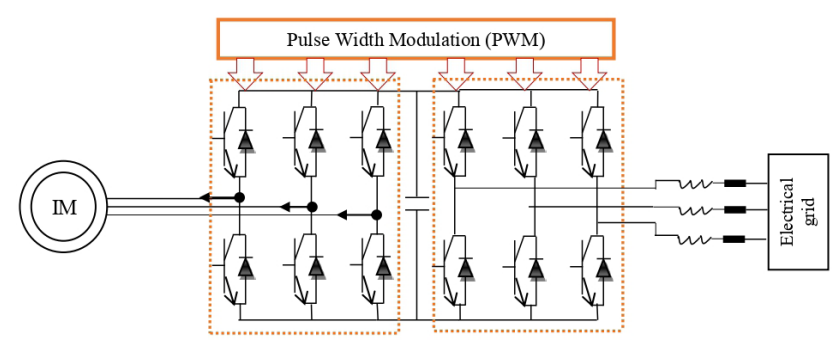

Fig. 1 Topology of conventional converter AC-DC-AC PWM

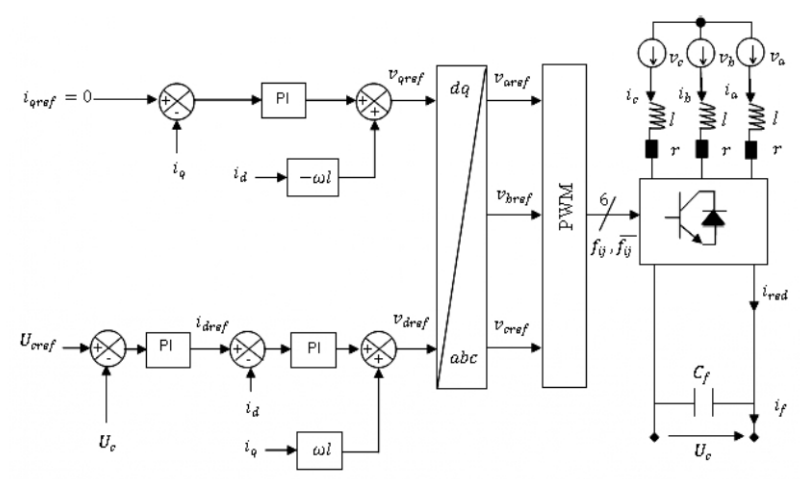

Fig. 2 Control of converter side grid

preferred for frequently applications operating in regenerative mode such as electric drives especially where the $\mathrm{AC}$ rectifier is part of the controller (Fig. 2). According to the closing or opening of the switches, $k_{i j}$ branch voltages can be equal to Uc or 0 . Introduces another variable $S_{11}, S_{21}$ and $S_{31}$ which taking 1 if the switch $k_{i 1}$ is closed or -1 if the switch opened (Fig. 3) [16-21]:

$\left[\begin{array}{l}v_{1 N} \\ v_{2 N} \\ v_{3 N}\end{array}\right]=U_{c} / 6\left[\begin{array}{ccc}2 & -1 & -1 \\ -1 & 2 & -1 \\ -1 & -1 & 2\end{array}\right]\left[\begin{array}{l}S_{11} \\ S_{21} \\ S_{31}\end{array}\right]$.

The rectified current can be written as:

$i_{\text {rec }}=\frac{S_{11}+1}{2} i_{a}+\frac{S_{21}+1}{2} i_{b}+\frac{S_{31}+1}{2} i_{c}$.

\subsection{Modeling of machine side converter}

The inverter is a power electronics converter that allows conversion from continuous to alternative. It works by forced commutation and designed generally based transistors:

$\left[\begin{array}{l}v_{1 N} \\ v_{2 N} \\ v_{3 N}\end{array}\right]=U_{c} / 6\left[\begin{array}{ccc}2 & -1 & -1 \\ -1 & 2 & -1 \\ -1 & -1 & 2\end{array}\right]\left[\begin{array}{l}f_{11} \\ f_{21} \\ f_{31}\end{array}\right]$.

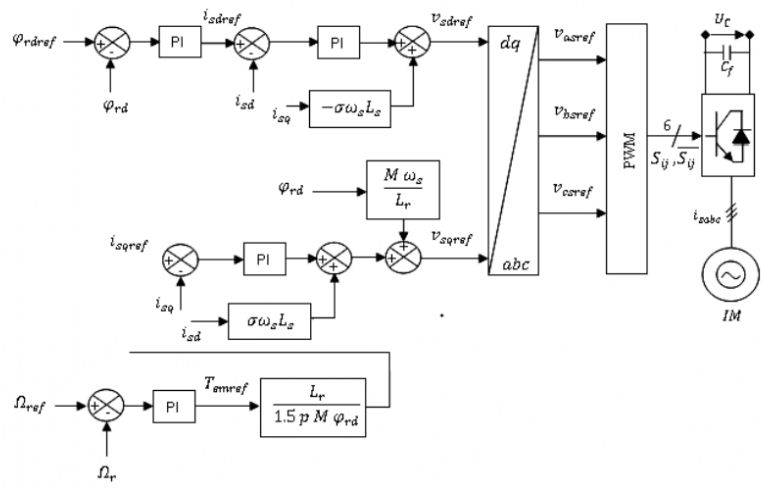

Fig. 3 Control of converter side machine 
The rectified current can be written as:

$i_{f}=\frac{f_{11}+1}{2} i_{a s}+\frac{f_{21}+1}{2} i_{b s}+\frac{f_{31}+1}{2} i_{c s}$.

\subsection{Modeling of the machine}

The equations which describe the dynamic behavior of asynchronous machine [6].

Stator voltage equation:

$\left\{\begin{array}{l}V_{s d}=R_{s} i_{s d}+\frac{d \phi_{s d}}{d t}-\omega_{s .} \phi_{s q} \\ V_{s q}=R_{s} i_{s q}+\frac{d \phi_{s q}}{d t}-\omega_{s .} \phi_{s d}\end{array}\right.$.

Rotor voltage equation:

$\left\{\begin{array}{l}V_{r d}=R_{r} i_{r d}+\frac{d \phi_{r d}}{d t}-\left(\omega_{s .}-\omega_{r}\right) \phi_{r q} \\ V_{r q}=R_{r} i_{r q}+\frac{d \phi_{r q}}{d t}-\left(\omega_{s .}-\omega_{r}\right) \phi_{r d}\end{array}\right.$.

Stator flux equation:

$\left\{\begin{array}{l}\phi_{s d}=L_{s} i_{s d}+M i_{r d} \\ \phi_{s q}=L_{s} i_{s q}+M i_{r q}\end{array}\right.$.

Rotor flux equation:

$\left\{\begin{array}{l}\phi_{r d}=L_{r} i_{r d}+M i_{s d} \\ \phi_{r q}=L_{r} i_{r q}+M i_{s q}\end{array}\right.$.

Torque equation:

$T_{e}=3 p M / 2 L_{r}\left(\phi_{r d} i_{s q}-\phi_{r q} i_{s d}\right)$.

\section{Fault tolerant system}

In case of fault occurrence in sensors, actuators or other parts of a complex system, conventional systems may produce undesirable results. In critical applications where the need for safety, reliability and fault tolerance is high, it is necessary to anticipate the fault tolerance ability against unpredicted faults to increase the reliability and availability of the system while providing acceptable performances $[10,13]$. These types of systems are known as the Fault Tolerant Systems (FTS). In the other words, an FTS can maintain the stability and acceptable performance after a fault occurrence. The performance of the system in normal and post-fault conditions may be different. An FTS may be based on redundancy or not. In an FTS with redundancy, a redundant part will replace the faulty part, after fault detection and upon reconfiguration. In this case, by correctly designing the FTS, the same operation capability can be obtained. However in some cases, some degree of performance degradation is accepted. In these cases, a suitable reconfiguration might be enough to assure the minimum required performance $[1,10,21]$.

After fault detection and isolation, a reconfiguration is necessary. Reconfiguration is required in both hardware and software parts of the system. Reconfiguration in the software part consists of modifying the references and the controller characteristics.

The system is composed of three-phase electrical sources and induction machine, with an AC-DC-AC fault tolerant converter between them. All different parts are explained further in detail.

\subsection{Six/five leg converter topology}

The studied converter is shows in Fig. 4 [14]. In normal operation (before the fault occurrence), the converter is a conventional back-to-back converter with three additional bidirectional switches (Fig. 4 (a)). These bidirectional switches are used for the converter reconfiguration after the fault isolation, i.e. before the fault occurrence these switches are all off. The converter configuration after a fault in one of the inverter legs is shown in Fig. 4 (b). In this case, the fault has been occurred at either $B_{31}$ or $B_{32}$. Depending on the application, each side of the converter can be connected to a source, load or machine. For example, in drive application, one side might be connected to a threephase source and the other will supply a three-phase machine. For a WECS with DFIG, side 2 will supply the rotor of the machine. In this paper, it is assumed that side 1

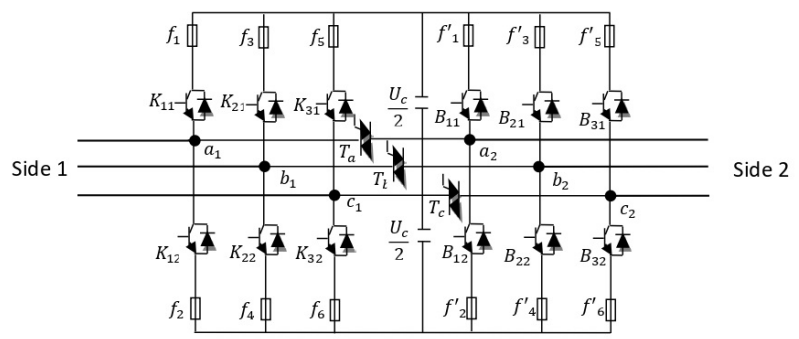

(a)

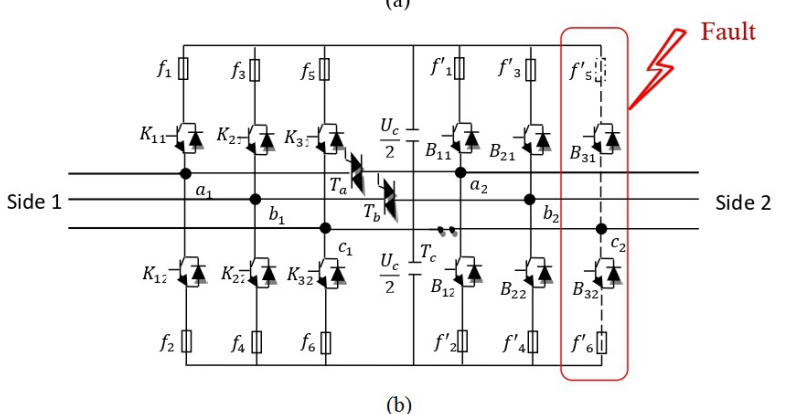

(b)

Fig. 4 Control of converter side machine 
of the converter is connected to a three-phase balanced sinusoidal source and the second side of the converter is connected to a balanced three-phase load.

It should be noted that the voltage producing capability in the five-leg converter is lower than the six-leg converter, meaning that with the same dc-link voltage, it can produce smaller three-phase voltages at its AC terminals, compared to the six-leg converter. Also the current rating in the shared leg of the converter is larger than in the other legs.

\subsection{Reconfigurable control of the converter}

Before the fault occurrence, the fault tolerant converter is performing as a conventional six-leg converter and any PWM method can be used for its control. After the fault detection and reconfiguration, one leg will be shared between the two sides of the converter and the faulty leg will be disconnected. So, the converter will become a five-leg structure. Among the several PWM approaches studied in the literature for this 5-leg post-fault topology, it seems that the suggested method in $[4,15]$. Therefore this approach is used in this paper.

In this method, a so called double zero-sequence injection method is performed. Voltage reference signals $v_{x i}^{*}(x \in\{a, b, c\}, i \in\{1,2\})$ for both sides of the converter are calculated using the appropriate methods depending on the targeted applications. Then, a Zero Sequence Signal (ZSS) is added to these values to form the modulation signals (Eq. (10)).

In fact, ZSS does not change the output line-to-line and phase voltages, therefore it is used as a degree of freedom to reduce the current harmonics and improve the dc-bus utilization:

$v_{x i}(t)=v_{x i}^{*}(t)+\operatorname{ZSS}_{i}(t)$,

where $v_{\text {zss }}(i \in\{1,2\})$ is the ZSS for side $i$.

ZSS signal for a three-phase system is computed as follows in Eq. (11):

$v_{\mathrm{ZSS}_{i}}(t)=-\frac{1}{2}\left[\begin{array}{l}\max \left(v_{a i}^{*}(t)+v_{b i}^{*}(t)+v_{c i}^{*}(t)\right) \\ +\min \left(v_{a i}^{*}(t)+v_{b i}^{*}(t)+v_{c i}^{*}(t)\right)\end{array}\right]$.

Since there is 6 voltage references and only 5 legs, a reduction in the number of voltage references is required. Reduction of the number of voltage references can be made by using an inverse lookup table $[2,11]$, this is realized by adding another ZSS in accordance to the converter configuration in five-leg mode.

The new set of voltage references assuming that two $c$ legs of the two sides are connected in the five-leg mode are calculated as:
$v_{A 1}=v_{a 1}+v_{c 2} ; v_{B 1}=v_{b 1}+v_{c 2}$
$v_{A 2}=v_{a 2}+v_{c 1} ; v_{B 2}=v_{b 2}+v_{c 1}$
$v_{c}=v_{c 1}+v_{c 2}$.

Since the same signal is added to all three reference values of the converter, the fundamental output voltage will not be affected. Fig. 5 shows the principle of this method. In Fig. 5 (a) the ZSS for a conventional converter is shown. This ZSS injection will be repeated for both sets of three phase voltage references at the two sides of the converter, then by using (Eq. (11)) a new set of five voltage references are produced and sent to the PWM unit, as shown in Fig. 5 (b).

\subsection{Voltage reference generation}

In fact, in healthy or faulty cases, the controls of both converters are not the same and must be changed as quickly as possible to avoid any discontinuity or transient in the currents The control unit of the 6/5 leg converter produces the reference voltages and sends them to the PWM blocks. For each application case, depending on the source/load connected at two sides of the converter, there are different methods for producing the reference voltages.

\subsection{Fault detection and reconfiguration}

Fast fault detection is essential for fault tolerant systems. Here the method detailed in our earlier contributions is used for detection of fault and its location [22]. Using this

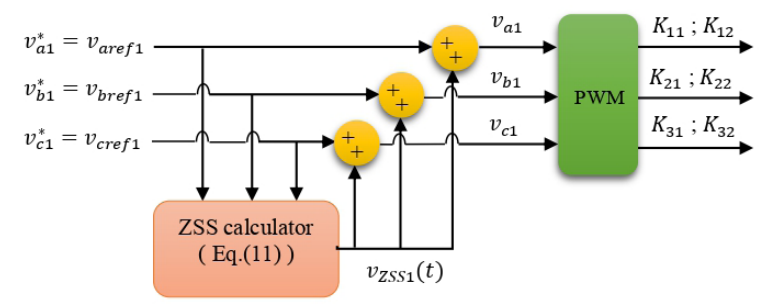

(a)

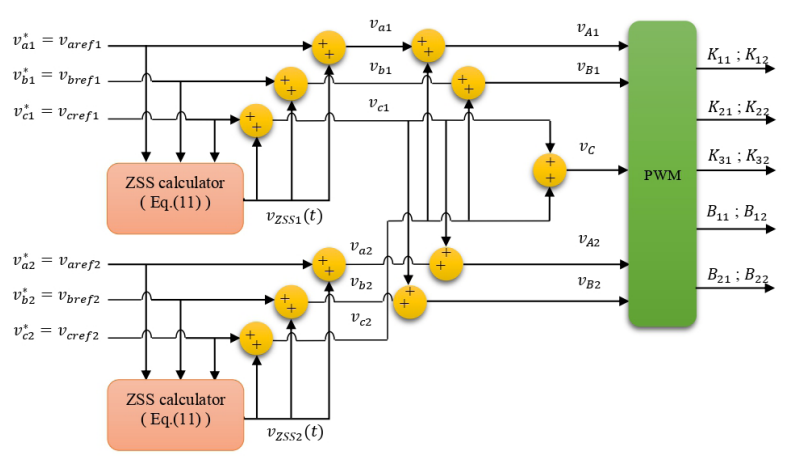

(b)

Fig. 5 (a) Principle of PWM module for one 4.4 converter; (b) for 5-leg converter when $B_{3}$ legs are shared 
method, it is possible to detect the fault quickly and efficiently. In [22] it is shown that the fault occurrence in each leg can be diagnosed by comparing the measured and estimated pole voltages.

However, in reality, due to measurement and discretizing errors, and mainly because of non-ideal behaviors of switches and drivers (turn-off and turn-on propagation time and dead time generated by the drivers), the voltage error is not zero during normal operation.

To avoid false fault detections, two adjustments are employed to compensate the effect of the measurement errors and delays. For this purpose, first the absolute value of the error between measured and estimated pole voltage is calculated. Then, this value applied to a comparator with a threshold value $h$, to determine if the difference between the measured and estimated voltages is large enough to be considered as an error. Then, this signal is applied to an up-counter that computes the number of pulses while the output of the first comparator is high. In the other words, the output of the upcounter corresponds to the time during which $v_{k n m}$ (measured voltage) and $v_{\text {knes }}$ (estimated voltage) are different $[7,13]$.

Consequently, the fault occurrence is detected using simultaneously a time criterion and a 'voltage criterion'. To do this, the up-counter output is applied to a second comparator with a threshold value of ' $N$ '. In this way, false fault detection due to semiconductor switching is avoided and fault can be detected very fast. Fig. 6 shows one leg of the converter, while there is an open-circuit fault in the upper switch. Note that in some cases, based on the direction of the current $i_{k}$, there might be a condition that $D_{k}$ conducts instead of $S_{k}$; therefore in this case, the converter operates normally and the fault cannot be detected. For example, while $T_{k}=1$ and $i_{k}<0, D_{k}$ is on. Here $T_{k}$ is the command

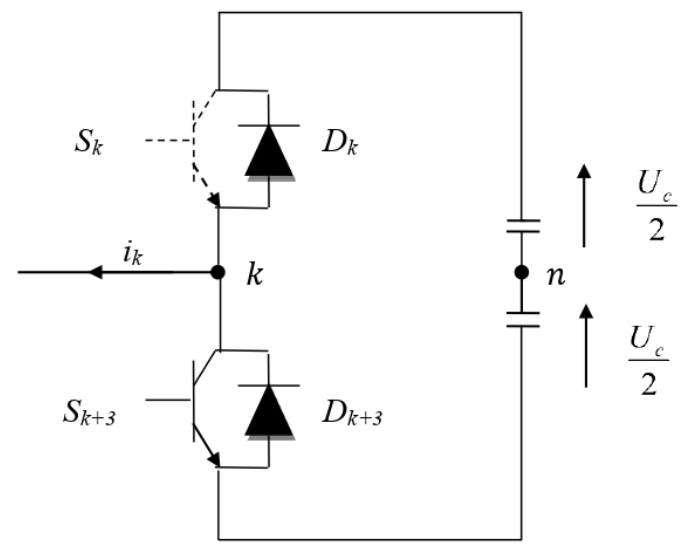

Fig. 6 One leg of converter during an open-circuit fault in the upper switch signal for the upper switch of the leg $k . T_{k}=0$ indicates that the switch is commanded to be open, whilst $T_{k}=1$ means that the switch is commanded to be closed. The switch commands in each leg are complementary. Lets now consider two converter legs as shown in Fig. 7 and suppose that there is a short circuit fault in $S_{k}$. When $T_{k}=1$ the leg $k$ operates normally. However when the $T_{k}=0$, the dc-link is short circuited. Fig. 7 (b) shows the short circuit path. The short circuit current is limited by only the short circuit resistance, which is a small value. That is why a suitable protection is needed in this case. In this case, if the fuse clearing time is smaller than the fault detection time, the faulty leg will be isolated by the fuses. If the fault is detected before the fuses act, the command of the faulty leg switches are set at zero and the corresponding bidirectional switch will be turned on. In this case, there is still at least one fuse in the short circuit path; therefore the short circuit will be cleared after fuse operation (Fig. 7 (c)).

\section{Simulation results}

We simulated the system studied by the following test. At first, we start our machine unloading $\Omega_{r e f}=100 \mathrm{rad}=\mathrm{s}$ then we inserting and removing a torque load $12 \mathrm{~N} \mathrm{~m}$

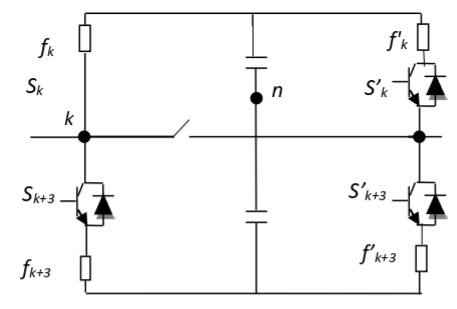

(a)
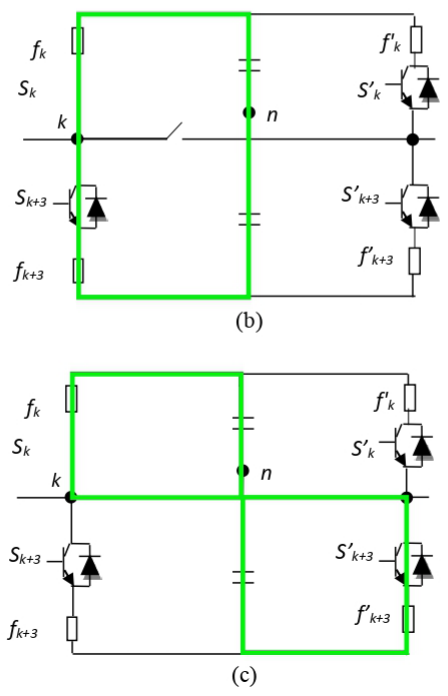

Fig. 7 Equivalent circuit for the leg " $k$ " (a) a short circuit fault in $S_{k}$; (b) short circuit path after the fault; (c) short circuit path when the fuse clearing time is larger than the fault detection time 
in instants $t=0.3 \mathrm{~s}$ and $t=0.7 \mathrm{~s}$ respectively, after we change direction of rotation $\Omega_{r e f}=-100 \mathrm{rad}=\mathrm{s}$ at $t=1 \mathrm{~s}$, after that we inserting and removing a torque load $-12 \mathrm{~N} \mathrm{~m}$ in instants $t=1.4 \mathrm{~s}$ and $t=1.7 \mathrm{~s}$ respectively.

We considered that the fault has occurred in the converter side machine in the $\operatorname{leg} B_{3}$ at $t=0.5 \mathrm{~s}$. The fault tolerant control is activated after $40 \mu \mathrm{s}$, by the homopolar injection method (ZSS) which ensures the continuity of service of our system. The obtained results are presented in the Fig. 8. We observed that the converter operates normally, as healthy system. DC bus voltage control stay stable (Fig. 9 (c)) (we constrained to increase the DC bus voltage to ensure the necessary capacity in the production of the three alternating voltages).

Fig. 9 (a) presents the line current in the input system, we can observe converter side grid before and after the fault detection and compensation, it is in phase with the voltage quasi sinusoidal and does not mark a significant peak.

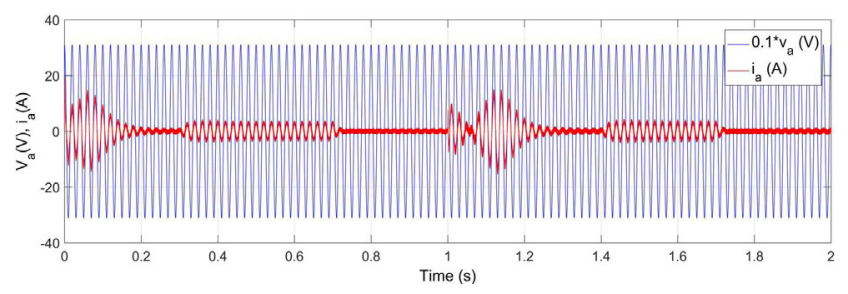

(a)

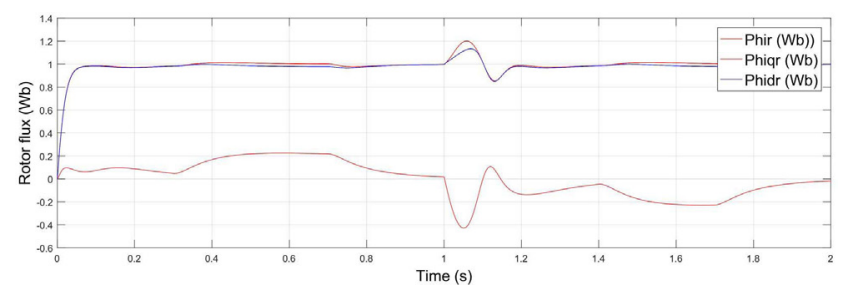

(c)

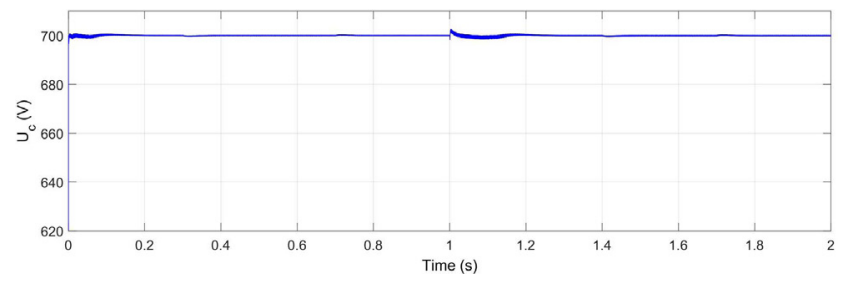

(e)

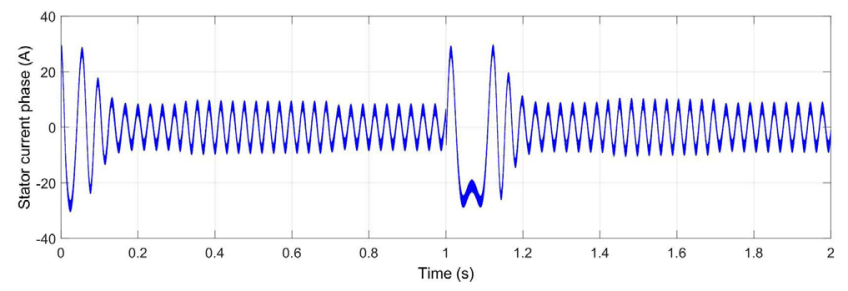

(g)
The other controlled quantities suit regularly their references (rotor speed, torque and flux). Also we can note that no noticeable deformation appears on the waveforms, because the time of fault detection and composition is shorter $(40 \mu \mathrm{s})$ than the commutation period of the switches.

The AC drive system configuration employs a fiveleg converter and can handle the failure of all the power switches connected to the positive or negative rail of the dc-link. The operation of drive in the post-fault is intended for short time periods to avoid problems related to losses and magnetization. However, the magnetization of the machine as resulted from its operation in the postfault condition can removed once the drive is repaired by designing a suitable Pulse Width Modulation pattern (Tables 1 and 2). The simulation results have demonstrated the feasibility of the proposed strategy for improving the reliability of a three phase AC motor drive system.

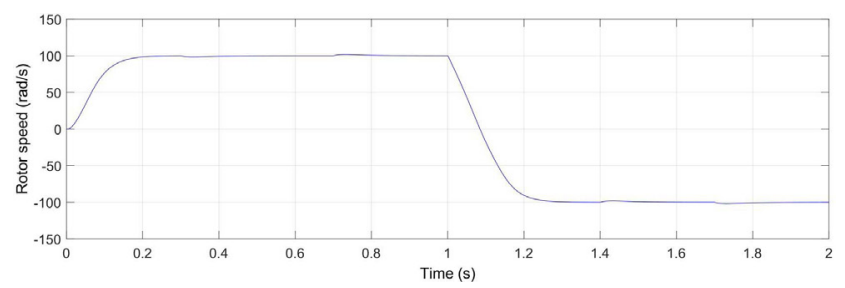

(b)

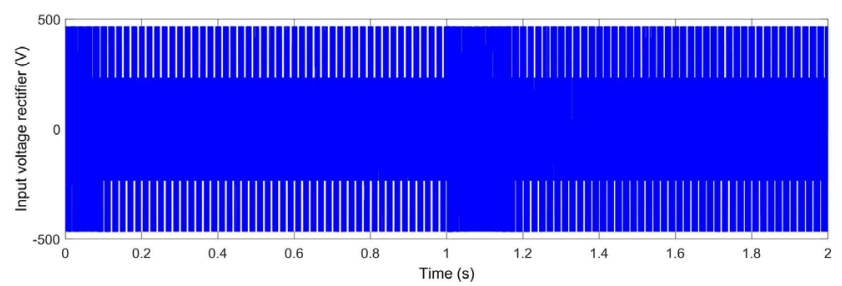

(d)

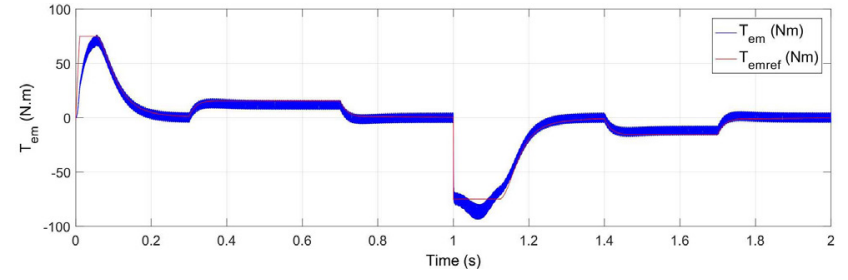

(f)

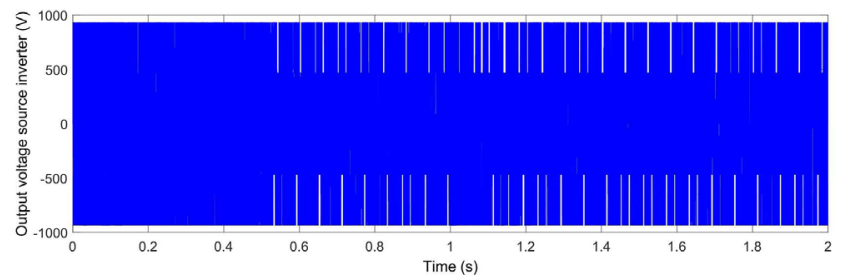

(h)

Fig. 8 Simulation results of the healthy system (a) Voltage and current sources, (b) Rotor speed, (c) Rotor flux, (d) Input voltage rectifier, (e) DC bus voltage control, (f) Electromagnetic torque, (g) Stator current phase, (h) Output voltage source inverter 


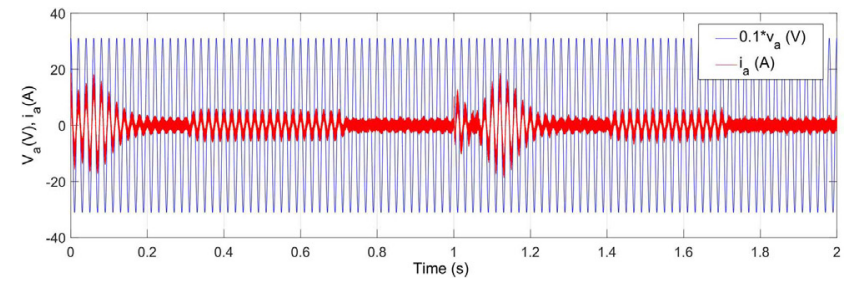

(a)

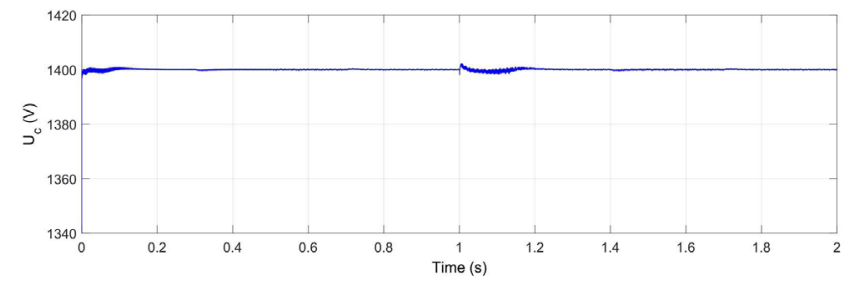

(c)

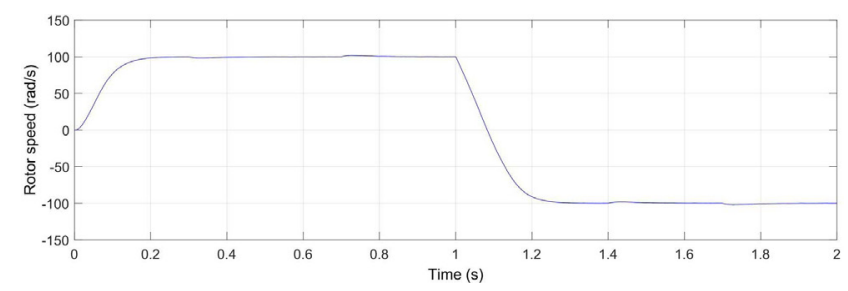

(e)

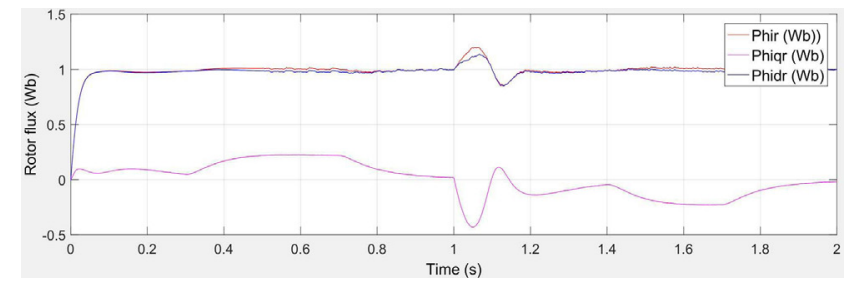

(g)

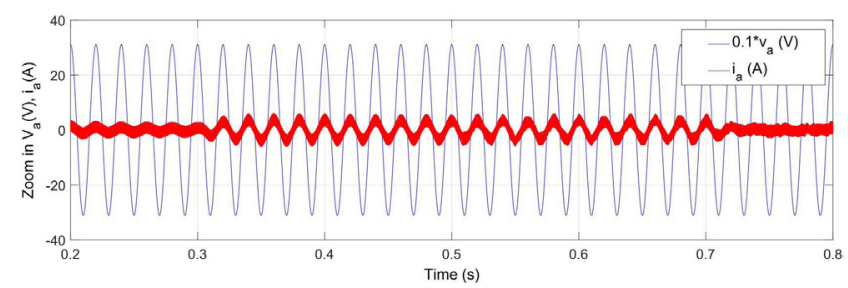

(b)

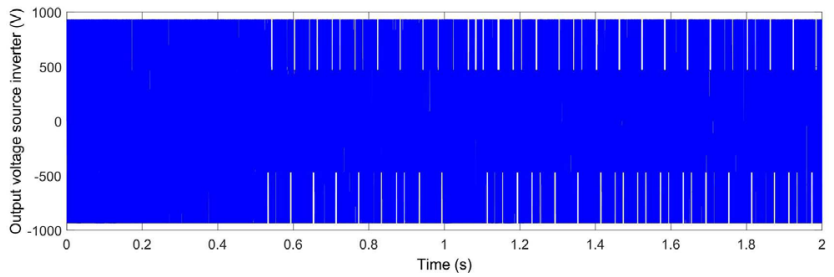

(d)

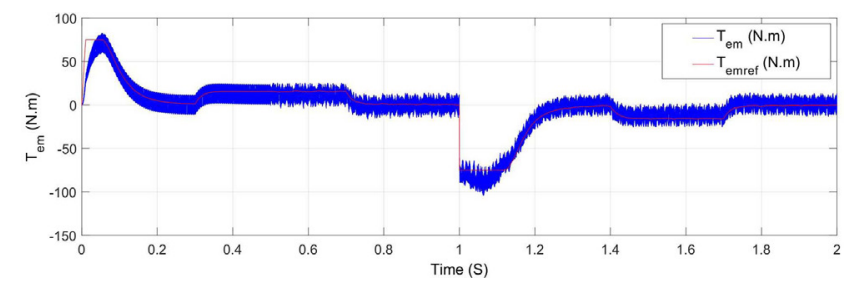

(f)

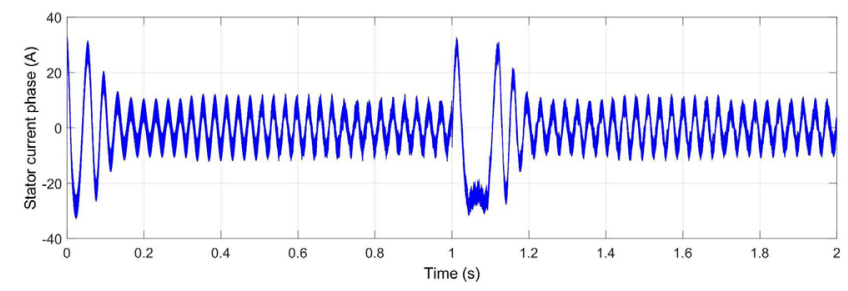

(h)

Fig. 9 Simulation results of topology 6/5 leg fault tolerant without redundancy leg (the fault has been occurred in $B_{3}$ ) (a) Voltage and current sources, (b) Zoom in voltage and current sources, (c) DC bus voltage control, (d) Output voltage source inverter, (e) Rotor speed, (f) Electromagnetic torque, (g) Rotor flux, (h) Stator current phase

Table 1 Induction motor parameters.

\begin{tabular}{lc}
\hline Numeric value of the parameter & Signification \\
\hline$R_{s}=3: 88$ & Stator resistance $(\Omega)$ \\
$R_{r}=1: 87$ & Rotor resistance $(\Omega)$ \\
$L_{s}=0: 252$ & Stator inductance $(\mathrm{H})$ \\
$L_{r}=0: 252$ & Rotor inductance $(\mathrm{H})$ \\
$L_{m}=0: 236$ & Magnetizing inductance $(\mathrm{H})$ \\
$J=0: 0266$ & Moment of inertia $\mathrm{kg}: \mathrm{m}^{2}$ \\
$P_{n}=2200$ & Nominal power $(\mathrm{W})$ \\
$p=2$ & Number of pole pairs \\
$V_{n}=220=380$ & Nominal voltage $(\mathrm{V})$ \\
\hline
\end{tabular}

Table 2 Parameters of electrical power source.

\begin{tabular}{lc}
\hline Numeric value of the parameter & Signification \\
\hline$f=50$ & Network frequency $(\mathrm{Hz})$ \\
$v=220$ & Simple network voltage $(\mathrm{V})$ \\
\hline
\end{tabular}

\section{Conclusion}

In this paper, we study the static converters three-phase ac-dc-ac voltage structure which are widely used in many power applications. The continuity of service of these systems, security, reliability and performance are now major concerns in this field related to energy. We devoted our study of the topology without redundancy leg converter "back-to-back" fault tolerant, with a very fast fault detection scheme and suited reconfigurable control is studied. The simulation results presented in this paper show the effectiveness of the fault tolerant control. This structure tolerating the presence of fault open circuit in one of the legs of the two side converter and remains constant after reconfiguration, fault converter without redundancy leg has the same ability of the pre-fault converter. 


\section{References}

[1] Extremiana, G., Abad, G., Arza, J. Torre, I. "Rotor flux oriented control of induction machine based drives with compensation for the variation of all machine parameters", Bulletin of the Polish Academy of Sciences: Technical Sciences, 61(2), pp. 309-324, 2013. https://doi.org/10.2478/bpasts-2013-0029

[2] Shahbazi, M., Zolghadri, M. R., Poure, P., Saadate, S. "Wind energy conversion system based on DFIG with open switch fault tolerant six-legs AC-DC-AC converter", In: 2013 IEEE International Conference on Industrial Technology (ICIT), Cape Town, South Africa, 2013, pp. 1656-1661.

https://doi.org/10.1109/ICIT.2013.6505922

[3] Dehghan, S. M., Amiri, A., Mohamadian, M., Andersen, M. A. E. "Modular space-vector pulse-width modulation for nine-switch converters", IET Power Electronics, 6(3), pp. 457-467, 2013. https://doi.org/10.1049/iet-pel.2012.0203

[4] Jones, M., Dujic, D., Levi, E. "A performance comparison of PWM techniques for five-leg VSIs supplying two-motor drives", In: 2008 34th Annual Conference of IEEE Industrial Electronics, Orlando, FL, USA, 2008, pp. 508-513. https://doi.org/10.1109/IECON.2008.4758005

[5] Frappé, E., De Bernardinis, A., Bethoux, O., Marchand, C., Coquery, G. "Action palliative par le convertisseur statique en cas de défaillance d'un générateur PAC modulaire de puissance" (Palliative action by the static converter in the event of failure of a modular heat pump generator), In: Electronique de Puissance du Futur (EPF 2010), Saint Nazaire, France, 2010, Article Number: hal-00615205. (in French)

[6] Sahraoui, K., Gaoui, B., Mokrani, L., Belarbi, K. "Fault tolerant control of redundant topology of PWM AC-DC-AC converter supplying an electromechanical drive", In: 2016 8th International Conference on Modelling, Identification and Control (ICMIC), Algiers, Algeria, 2016, pp. 374-380.

https://doi.org/10.1109/ICMIC.2016.7804140

[7] Jacobina, C. B., De Freitas, I. S., Da Silva, E. R. C., Lima, A. M. N., Ribeiro, R. L. A. "Reduced Switch Count DC-Link ACAC FiveLeg Converter", IEEE Transactions Power Electronics, 21(5), pp. 1301-1310, 2006.

https://doi.org/10.1109/TPEL.2006.880307

[8] Sae-Kok, W., Grant, D. M., Williams, B. W. "System reconfiguration under open-switch faults in a doubly fed induction machine", IET Renewable Power Generation, 4(5), pp. 458-470, 2010. https://doi.org/10.1049/iet-rpg.2010.0005

[9] Peng, T., Dan, H., Yang, J., Deng, H., Zhu, Q., Wang, C., Gui, W., Guerrero, J. M. "Open-Switch Fault Diagnosis and Fault Tolerant for Matrix Converter With Finite Control Set-Model Predictive Control", IEEE Transactions on Industrial Electronics, 63(9), pp. 5953-5963, 2016. https://doi.org/10.1109/TIE.2016.2558139

[10] Sahraoui, K., Kouzi, K., Ameur, A. "A Robust Sensorless Iterated Extended Kalman Filter for Electromechanical Drive State Estimation", Electrotehnică, Electronică, Automatică, 65(2), pp. 46-53, 2017.

[11] Daigavane, M. B., Vaishnav S. R., Shriwastava R. G. "Sensorless Field Oriented Control of PMSM Drive System for Automotive Application", In: 2015 7th International Conference on Emerging Trends in Engineering \& Technology, Kobe, Japan, 2015, pp. 106-112. https://doi.org/10.1109/ICETET.2015.11
[12] Karimi, S., Gaillard, A. Poure, P., Saadate, S. "FPGA-Based Real-Time Power Converter Failure Diagnosis for Wind Energy Conversion Systems", IEEE Transactions on Industrial Electronics, 55(12), pp. 4299-4308, 2008. https://doi.org/10.1109/TIE.2008.2005244

[13] Shahbazi, M., Poure, P., Saadate, S., Zolghadri, M. R. "Five-leg converter topology for wind energy conversion system with doubly fed induction generator", Renewable Energy, 36(11), pp. 3187-3194, 2011.

https://doi.org/10.1016/j.renene.2011.03.014

[14] Jacobina, C. B., de Araujo Ribeiro, R. L., Lima, A. M. N., da Silva, E. R. C. "Fault-tolerant reversible AC motor drive system", IEEE Transactions on Industry Applications, 39(4), pp. 1077-1084, 2003. https://doi.org/10.1109/TIA.2003.814567

[15] Jones, M., Vukosavic, S. N., Dujic, D., Levi, E., Wright, P. "Five-leg inverter PWM technique for reduced switch count two-motor constant power applications", IET Electric Power Applications, 2(5), pp. 275-287, 2008. https://doi.org/10.1049/iet-epa:20070497

[16] Rodrigues, P. L. S., Jacobina, C. B., de Freitas, N. B. "Single-phase universal active power filter based on ac-dc-ac converter with eight controlled switches", IET Power Electronics, 12(5), pp. 1131-1140, 2019. https://doi.org/10.1049/iet-pel.2018.5391

[17] Sahraoui, K., Gaoui, B., Mokrani, L., Belarbi, K. "Fast detection control for fault-tolerant converter back-to-back with redundancy leg supplying an induction motor drives", International Journal of Digital Signals and Smart Systems (IJDSSS), 2(1), pp. 15-35, 2018. https://doi.org/10.1504/IJDSSS.2018.090869

[18] Malinowski, A., Yu, H. "Comparison of Embedded System Design for Industrial Applications", IEEE Transactions on Industrial Informatics, 7(2), pp. 244-254, 2011. https://doi.org/10.1109/TII.2011.2124466

[19] Shahbazi, M., Poure, P., Saadate, S., Zolghadri, M. R. "FPGA-Based Reconfigurable Control for Fault-Tolerant Back-to-Back Converter Without Redundancy", IEEE Transactions on Industrial Electronics, 60(8), pp. 3360-3371, 2013. https://doi.org/10.1109/TIE.2012.2200214

[20] Shahbazi, M., Saadate, S., Poure, P., Zolghadri, M. R. "Open-circuit switch fault tolerant wind energy conversion system based on six/ five-leg reconfigurable converter", Electric Power Systems Research, 137, pp. 104-112, 2016.

https://doi.org/10.1016/j.epsr.2016.04.004

[21] Bastos, R. R., de Souza, T. S., de Jesus Cardoso Filho, B. "Modulation Effects in an Inverter Fed Nine-phase Induction Motor Drive", IEEE Transactions on Industry Applications, Article Number: 2938739. https://doi.org/10.1109/TIA.2019.2938739

[22] Koo, G. W., Joo, D., Lee, B. K. "Enhanced Threshold Point Calculation Algorithm for Switch Fault Diagnosis in Grid Connected 3-Phase AC-DC PWM Converters", Energies, 12(10), Article Number: 1979, 2019. https://doi.org/10.3390/en12101979 